\title{
Quality of life among elderly patients undergoing transcatheter or surgical aortic valve replacement- a model-based longitudinal data analysis
}

Klaus Kaier ${ }^{1,2^{*}}$ (D), Anja Gutmann², Hardy Baumbach ${ }^{3}$, Constantin von zur Mühlen², Philip Hehn', Werner Vach', Friedhelm Beyersdorf ${ }^{4}$, Manfred Zehender ${ }^{2}$, Christoph Bode ${ }^{2}$ and Jochen Reinöhl ${ }^{2}$

\begin{abstract}
Background: Quality of life (QoL) measurements reported in observational studies are often biased, since patients who failed to improve are more likely to be unable to respond due to death or impairment. In order to observe the development of QoL in patients close to death, we analyzed a set of monthly QoL measurements for a cohort of elderly patients treated for aortic valve stenosis (AS) with special consideration of the effect of distance to death.

Methods: QoL in 169 elderly patients (age $\geq 75$ years), treated either with transcatheter aortic valve replacement (TAVR; $n=92)$, surgical aortic-valve replacement $(n=70)$, or drug-based therapy $(n=7)$, was evaluated using the standardized EQ-5D questionnaire. Over a two-year period, patients were consulted using monthly telephone interviews or outpatient visits, leading to a total of 2463 time points at which QoL values, New York Heart Association (NYHA) Functional Classification and their status of assistance were assessed. Furthermore, postprocedural clinical events and complications were monitored. Linear and ordered logistic regression analyses with random intercept were carried out, taking into account overall trends and distance to death.

Results: QoL measures decreased slightly over time, were temporarily impaired at month 1 after the initial episode of hospitalization and decreased substantially at the end of life with a measurable effect starting at the sixth from last follow-up (month) before death. Many clinical complications (bleeding complications, stroke, acute kidney injury) showed an impairment of QoL measurements, but the inclusion of lagged variables demonstrated medium term (three months) QoL impairments for access site bleeding only. All other complications are associated with event-related impairments that decreased dramatically at the second and third follow-up interviews (month) after event.
\end{abstract}

Conclusions: Distance to death shows clear effects on QoL and should be taken into account when analyzing QoL measures in the elderly patients treated for aortic valve stenosis.

Trial registration: German Clinical Trial Register Nr. DRKS00000797

Keywords: Quality of life, EQ-5D, Transcatheter aortic valve implantation, TAVI, Transcatheter aortic valve replacement, TAVR, Aortic valve replacement, AVR

\footnotetext{
* Correspondence: kaier@imbi.uni-freiburg.de

${ }^{1}$ Institute of Medical Biometry and Statistics, Faculty of Medicine and Medical

Center - University of Freiburg, Stefan-Meier-Str. 26, D-79104 Freiburg,

Germany

${ }^{2}$ Department of Cardiology, Heart Center Freiburg University, Freiburg,

Germany

Full list of author information is available at the end of the article
} 


\section{Background}

The prevalence of acquired aortic valve stenosis (AS) is on the rise in the ageing populations of the developed countries $[1,2]$. Functional and quality of life (QoL) impairment as well as mortality are extremely high among symptomatic patients, and the survival and QoL benefits of surgical (SAVR) and transcatheter aortic valve replacement (TAVR) have been shown previously [3-5].

A number of studies have been published in recent years on QoL among patients with aortic valve stenosis, most of which focus on the newly available TAVR procedure. Several recent reviews provide an overview of the body of evidence and its strengths and weaknesses [6-12].

Unfortunately, these reviews report a varying and often poor quality of studies $[9,10,12]$ and find many (observational) studies to be subject to survivor bias [7, 8, 10]: The cohort of patients filling out QoL questionnaires at follow-up is disproportionately composed of those who benefitted from the procedure, since patients who failed to improve are more likely to be unable to respond due to death or impairment. In addition, patient co-morbidities and available follow-up time frames are highly diverse, which underlines the need for further studies with repeated QoL measurements over a longer time period.

In this study, we aim to bridge this gap of knowledge by evaluating QoL measurements among high-risk patients with severe symptomatic aortic valve stenosis taken in the course of the prospective, medicaleconomic TAVI Calculation of Costs Trial (TCCT). We used monthly QoL measurements over a two year period in 169 patients in order to analyze the impact of clinical complications on QoL values, taking into account differences between treatment groups, overall trends and distance to death.

\section{Methods \\ Data collection}

The TAVI Calculation of Costs Trial (TCCT), which this study is based on, was designed as a prospective observational multicenter cohort study on elderly patients with symptomatic AS receiving either SAVR, TAVR, or best medical therapy (DRUG). This study has been approved by the institutional ethics committee (Research Ethics Committee Albert-Ludwigs-Universität Freiburg, Germany ID: 52/11), and registered in the German Clinical Trial Register (ID: DRKS00000797). All patients referred to our centers between April 2011 and October 2013 were considered for inclusion into the study. Age above 75 years was deliberately chosen as an inclusion criterion. All treatment decisions were made by a study-independent "heart team" of cardiac surgeons and cardiologists according to best clinical practice [13].
A primary focus of the study was to evaluate QoL before and after procedure as well as during a 2-year follow-up period using the EQ-5D questionnaire, a standardised instrument to measure health outcome whose design emphasizes simplicity and quick completion, improving its feasibility and thereby response rates from this study's severely health-impaired patient population [14]. EQ-5D Index values were calculated using the established German calculation formula which is based on time trade off values [15]. A total of 2463 questionnaires were completed by 169 elderly patients treated with either transcatheter aortic valve replacement (TAVR, $N=92$, of which 30 received TAVI via the transapical approach), surgical aortic valve replacement (SAVR, $N=70$, of which 17 received additional bypass grafting and/or mitral valve replacement), or drug-based therapy (DRUG, $N=7$ ), who were tracked using monthly telephone interviews. Cardiovascular and non-cardiovascular complications, prosthetic valve associated endpoints, and therapy-specific endpoints were assessed according to the revised definitions provided by the Valve Academic Research Consortium (VARC-2) [16].

\section{Statistical analysis}

Differences between treatment groups were analyzed using the non-parametric Wilcoxon rank-sum test. Linear and ordered logistic regression analyses with a random intercept were carried out for the EQ-5D questionnaire's EQ-5D $D_{\text {Index }}$ (continuous endpoint, $0=$ worst state, 1 = best state), the 5 EQ-5D dimensions (order categorical endpoint, $1=$ no problems, 2 = some problems, 3 = extreme problems), patients heart function according to the New York Heart Association (NYHA) Functional Classification and the Canadian Cardiovascular Society (CCS) Angina Grading Scale. In addition, the current status of assistance at follow-up was retrieved and an order categorical variable was built with the following characteristics: 1 (no external help or intra-familial help only), 2 (assisted living and/or home care services) and 3 (short or long-term care or temporal hospitalization). Distance to death was modeled as a categorical variable for the last six months before death. With respect to EQ-5D Index values during follow up, overall measurement compliance was $56.6 \%$, with 85 \% compliance during the first three months, $\sim 80 \%$ compliance during the first six months, and $\sim 73 \%$ compliance during the first year, but only $\sim 40 \%$ compliance during the second year. In addition, there are a number of missing values with respect to EQ-5D dimensions, patients heart function, their current status of assistance and clinical complications. With respect to these missing values no imputation method was applied.

All analyses were performed using Stata 14 (Stata Corp., Texas. USA). 


\section{Results}

As treatment decisions were based on clinical judgement according to patient presentation and the assessment of a "heart team" there were substantial differences between groups. SAVR patients were significantly younger $(p<0.01)$ and exhibited significantly lower EuroScore I values $(p<0.01)$ than TAVR patients. In contrast, QoL values at baseline did not differ significantly between TAVR and SAVR patients $(p=0.41)$. See Table 1 for an overview of pre- and post-procedural parameters.

Table 1 Baseline and post-procedural monthly parameters

Baseline and post-procedural parameters $(N=169)$

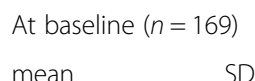

Age (in years)

logistic EuroSCORE

5 EQ-5D dimensions

Mobility

Self-Care

Usual Activities

Pain/Discomfort

Anxiety/Depression

Heart Function

CCS SCORE

Current status of the assistance or intra-familial help only

$77 \%$

No problems
$50 \%$
$79 \%$
$53 \%$
$51 \%$
$64 \%$
Mean
2.57
1.23
No external help
or intra-familial
help only
$77 \%$

Cardiological events among TAVI In-hospital and AVR patients

ASB life threatening/disabling

ASB major/minor

NASB life threatening/disabling

NASB major/minor

VASC major/minor

Stroke/TIA

AKIN 1

AKIN 2

AKIN 3

Severe cardiac dysrhythmia

Other complications

$\begin{array}{lll} & \text { At baseline }(n=169) \\ & \text { Mean } & \text { SD } \\ \text { HrQoLIndex } & 0.78 & 0.23\end{array}$

NYHA SCORE
11.54
During follow-up ( $n=2294)$

$\begin{array}{ll}\text { Mean } & \text { SD } \\ 0.77 & 0.25\end{array}$

0.25

Some problems Extreme problems

No problems

$50 \%$

$0 \%$

$2 \%$

$8 \%$

$8 \%$

$6 \%$

$30 \%$

SD

0.7

1.32

Assisted living and/or home care services

$13 \%$

Post-discharge
Short or long-term care or temporal hospitalization

$10 \%$
$39 \%$

$70 \%$

$44 \%$

$33 \%$

$69 \%$

Mean

1.36

0.5

No external help or intra-familial help only

$73 \%$
Some problems Extreme problems $58 \% \quad 3 \%$

$24 \% \quad 6 \%$

$44 \% \quad 12 \%$

$62 \% \quad 5 \%$

$28 \% \quad 3 \%$

SD

1.08

0.83

Assisted living and/or home care services

$18 \%$
Short or long-term care or temporal hospitalization

The EQ-5DIndex is a continuous variable between 0 and $1(0=$ worst state, 1 = best state). The 5 EQ-5D dimensions as shown in Model ( 2 ) to model (6) are categorical variables ( $1=$ no problems, $2=$ some problems, $3=$ extreme problems). Canadian Cardiovascular Society (CCS) Angina Grading Scale is a categorical variable between 1 (angina only during strenuous or prolonged physical activity) and 4 (inability to perform any activity without angina). New York Heart Association (NYHA) Functional Classification is a categorical variable between 1 (cardiac disease, but no symptoms and no limitation in ordinary physical activity) and 4 (severe limitations, experiences symptoms even while at rest). The current state of assistance is a categorical variable with 1 (no external help or intra-familial help only), 2 (assisted living and/or home care services) and 3 (short or long-term care or temporal hospitalization). ASB access site bleeding, NASB non-access site bleeding, VASC vascular complication, AKIN acute kidney injury 


\section{Overall, post-discharge and distance-to-death effects during the study period}

In Fig. 1, the results of a linear regression analysis with a random intercept at the patient level and observational time (in moths) as a categorical covariate are shown.

Over the two-year study period, three main effects were observed. Firstly, QoL measures decreased slightly over time. Secondly, QoL measures were substantially impaired at month 1 after the initial episode of hospitalization. In addition, 39 cases of mortality were reported during follow-up. Of the 39 cases of mortality, $20 \%$ died during the first month post discharge, $33 \%$ died during the first three months post discharge, $49 \%$ died during the first six months post discharge, $78 \%$ died during the first year post discharge and $90 \%$ died during the first 18 months post discharge. QoL decreased substantially at the end of life with a measurable amount starting at the sixth from last follow-up (month) before death. ${ }^{1}$ Table 2 summarizes these three effects on EQ-5D $D_{\text {Index }}$ values and also shows to which degree the five EQ-5D dimensions (model (2) to (6)) and measures of heart function (model (7) and (8)) are affected by these effects. At the last follow-up before death, for instance, $\mathrm{EQ}-5 \mathrm{D}_{\text {Index }}$ values are most impaired by an average of $-0.495(p<0.001)$ irrespective of time- and post-discharge effects. The same is true for all $5 \mathrm{EQ}-5 \mathrm{D}$ dimensions (see model (2) to (6) in Table 2) as well as measures of heart function (see model (7) and (8) in Table 2) and the current state of assistance (see model (9) in Table 2). In addition, the current state of assistance is target to a monthly trend, meaning that the risk for worsening of the status of assistance increases by every month of the two year study period (OR 1.06, $p<0.05)$. The same is true for the EQ-5D dimensions of mobility and pain as well as the heart function measured by the NYHA Functional Classification. At month 1 after the initial episode of hospitalization, nearly all QoL measures were substantially impaired, which is also true for the NYHA Functional Classification (OR1.94, $p<0.01)$ and the current status of assistance (OR 2.65, $p<0.01$ ). Although both consist of four categories, the NYHA functional classification seems to be more sensitive to trend, post-discharge and time-to-death effects than the CCS grading scale.

\section{Between-group differences and baseline-adjustment over the two-year period}

According to the European Society of Cardiology/ European Association for Cardio-Thoracic Surgery (ESC/EACTS) Guidelines [17], TAVR is recommended for patients considered unsuitable for conventional surgery because of severe comorbidities. In patients considered to be at high risk for conventional surgery, these comorbidities and the associated individual patient's risk should be assessed by a "heart team" of cardiac surgeons and cardiologists to select the most optimal treatment strategy for individual patients [17]. As a result of this modus operandi, treatment decision is associated with systematic risk selection and the logistic EuroSCORE has previously been shown to be of relevance for predicting both treatment decisions and overall survival [13]. Interestingly, when predicting follow-up QoL measures rather than survival, baseline values of the respective QoL measure had a more dominant impact on future values of any of the observed measures than risk profiles in comparison to

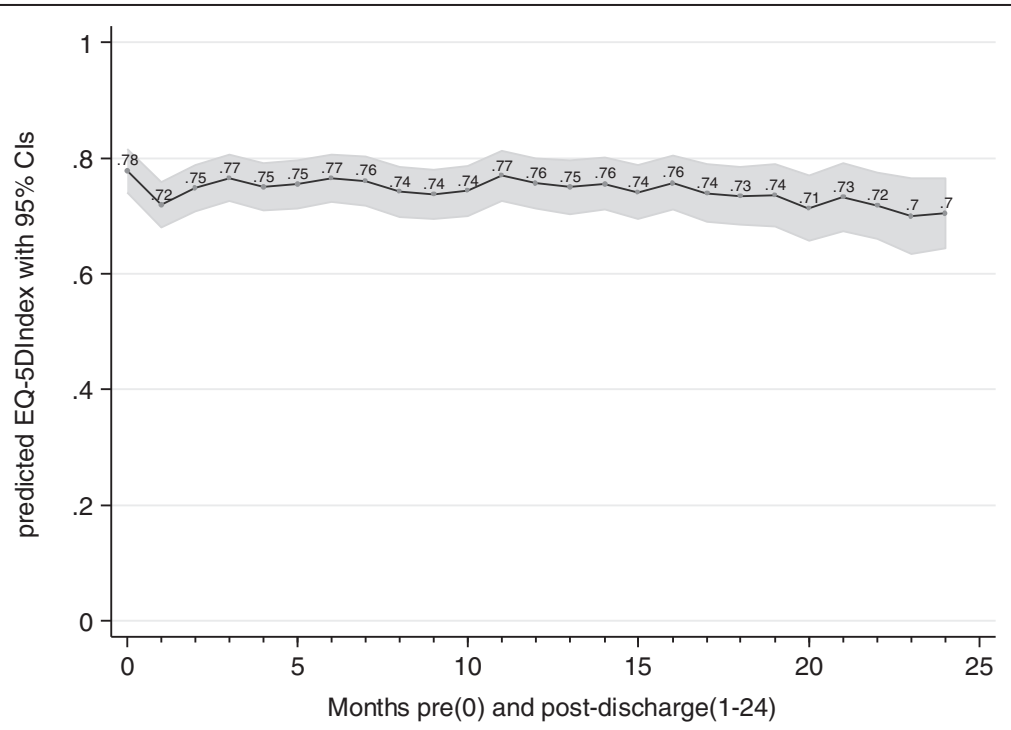

Fig. 1 Predicted EQ-5D Index values over the study period 
Table 2 Development of patient HRQOL over time and by distance to death

\begin{tabular}{|c|c|c|c|c|c|c|c|c|c|}
\hline & Quality of life & & & & & & Heart fu & Inction & Status of \\
\hline & EQ-5D Index & Five EQ- 5 & 5D dimensions & & & & & & \\
\hline & (1) & (2) & (3) & (4) & (5) & (6) & (7) & (8) & (9) \\
\hline & $E Q-5 D_{\text {Index }}$ & Mobility & $\begin{array}{l}\text { Looking after } \\
\text { myself }\end{array}$ & $\begin{array}{l}\text { Doing usual } \\
\text { activities }\end{array}$ & $\begin{array}{l}\text { Having pain or } \\
\text { discomfort }\end{array}$ & $\begin{array}{l}\text { Feeling worried, } \\
\text { sad or unhappy }\end{array}$ & $\begin{array}{l}\text { NYHA } \\
\text { score }\end{array}$ & $\begin{array}{l}\text { CCS } \\
\text { score }\end{array}$ & $\begin{array}{l}\text { Status of } \\
\text { assistance }\end{array}$ \\
\hline & Point estimate & Odds rat & ios from the ord & dered logistic & regression model & & & & \\
\hline Last follow-up before death & $-0.495^{* * *}$ & $85.56^{* * *}$ & $210.2^{* * *}$ & $79.70^{* *}$ & $23.66^{* * *}$ & $44.06^{* * *}$ & 4.653 & 1.258 & $189.7^{* * *}$ \\
\hline Second last follow-up before death & $-0.305^{* * *}$ & $14.40^{* *}$ & $26.95^{* * *}$ & $7.132^{*}$ & $16.94^{* * *}$ & $15.65^{* * *}$ & 2.042 & 2.203 & $18.08^{*}$ \\
\hline Third from last follow-up before death & $-0.221^{* * *}$ & 11.96 & $23.42^{* * *}$ & 6.753 & 2.672 & 3.567 & $5.171^{* *}$ & 1.477 & $58.83^{* * *}$ \\
\hline Fourth from last follow-up before death & $-0.204^{* * *}$ & $8.480^{*}$ & $10.11^{* *}$ & 6.338 & 3.433 & $8.167^{* *}$ & 1.807 & 1.911 & $22.58^{* * *}$ \\
\hline Fifth from last follow-up before death & $-0.139^{* *}$ & 5.282 & $12.73^{* *}$ & 8.027 & 1.384 & 2.331 & 1.169 & 1.247 & $21.37^{*}$ \\
\hline Sixth from last follow-up before death & $-0.0983^{*}$ & 2.033 & 3.203 & 2.902 & 2.918 & 3.273 & 1.464 & 0.996 & 7.387 \\
\hline Overall trend & -0.00143 & $1.083^{* * *}$ & 1.040 & 0.963 & $1.042^{* * *}$ & 0.979 & $1.053^{* * *}$ & 1.024 & $1.060^{*}$ \\
\hline Month 1 post-discharge & $-0.0460^{* *}$ & $2.878^{* * *}$ & $2.358^{*}$ & $2.273^{* *}$ & 1.391 & 1.487 & $1.939^{* *}$ & 1.197 & $2.652^{*}$ \\
\hline Constant & $0.789^{* * *}$ & & & & & & & & \\
\hline$N$ & 2294 & 2328 & 2332 & 2330 & 2330 & 2317 & 2252 & 2254 & 1980 \\
\hline
\end{tabular}

${ }^{*} p<0.05,{ }^{* *} p<0.01,{ }^{* * *} p<0.001$

The EQ-5D Index is a continuous variable between 0 and $1(0=$ worst state, $1=$ best state). The 5 EQ-5D dimensions as shown in Model (2) to model (6) are order categorical variables $(1=$ no problems, $2=$ some problems, $3=$ extreme problems). Canadian Cardiovascular Society (CCS) Angina Grading Scale is an order categorical variable between 1 (angina only during strenuous or prolonged physical activity) and 4 (inability to perform any activity without angina). New York Heart Association (NYHA) Functional Classification is an order categorical variable between 1 (cardiac disease, but no symptoms and no limitation in ordinary physical activity) and 4 (severe limitations, experiences symptoms even while at rest). The current state of assistance is an order categorical variable with 1 (no external help or intra-familial help only), 2 (assisted living and/or home care services) and 3 (short or long-term care or temporal hospitalization)

the logistic EuroSCORE (see Table 3, where values of the dependent variables at baseline and EuroSCORE values at baseline were included as time-invariant variables). Interestingly, the impact of baseline values on the respective dependent variable seems to persist over the entire twoyear period. ${ }^{2}$

Furthermore, a number of between-group differences may be observed. In comparison to TAVR patients, SAVR patients report more favorable QoL measures (see model (1) to (6) in Table 3), and, (or maybe because of this), a reduced risk for worsening of the status of assistance is recorded for them (OR 0.0441, $p<0.001$ ). On the other hand, an increased risk for limitations in the heart function is recorded for the few patients in the Drug group (see model (7) and (8) in Table 3). Please note that these between-group differences in QoL measures should not, or at least only in part, be interpreted as treatment effects, as the different treatment groups are not randomly assigned but subject to a risk-driven patient selection which may not be fully addressed by the applied baseline-adjustment.

\section{Clinical events and complications}

As shown in Table 1, a number of clinical events were recorded for TAVR and SAVR-patients, of which nearly $80 \%$ occurred during the initial episode of hospitalization. In order to analyze the impact of such events in the short and medium term, Drug patients were excluded from the analyses. As shown in model (1) in Table 4, QoL is most affected by life threatening non-access site bleeding (onemonth change: $-0.447, p<0.001$ ), stroke (one-month change: $-0.161, p<0.05)$ and stage 3 acute kidney injury (one-month change: $-0.177, p<0.01$ ). Interestingly, only life threatening non-access site bleeding was associated with a more intense status of assistance. In a next step, we analyzed the medium term impact of the respective complications. Therefore, categorizations of variables included in Table 5 were restructured by pooling complications of minor interest in 'other complications'. Then, lagged variables were included in order to capture the medium term impact of the respective complications. As shown in Table 5 model (2), time lags of up to three months were included in the analyses ${ }^{3}$. Interestingly, the impact of lagged effects on EQ-5D $\mathrm{D}_{\text {Index }}$ values remained significant for life threatening access site bleeding only. Other complications, such as life threatening non-access site bleeding (non-ASB), stroke, and stage 2 and stage 3 acute kidney injury (AKIN 2 and 3), are still associated with substantial effects impairments of EQ- $5 D_{\text {Index }}$ values at the first follow-up interview after event, but the event-related impairments decrease dramatically at the second and third follow-up interviews after event. In Table 5 we also consider the impact of two different strategies to take the influence of the distance to death into account: We may just 
Table 3 Between-group differences and baseline adjustment when analyzing QoL measures among patients with AS

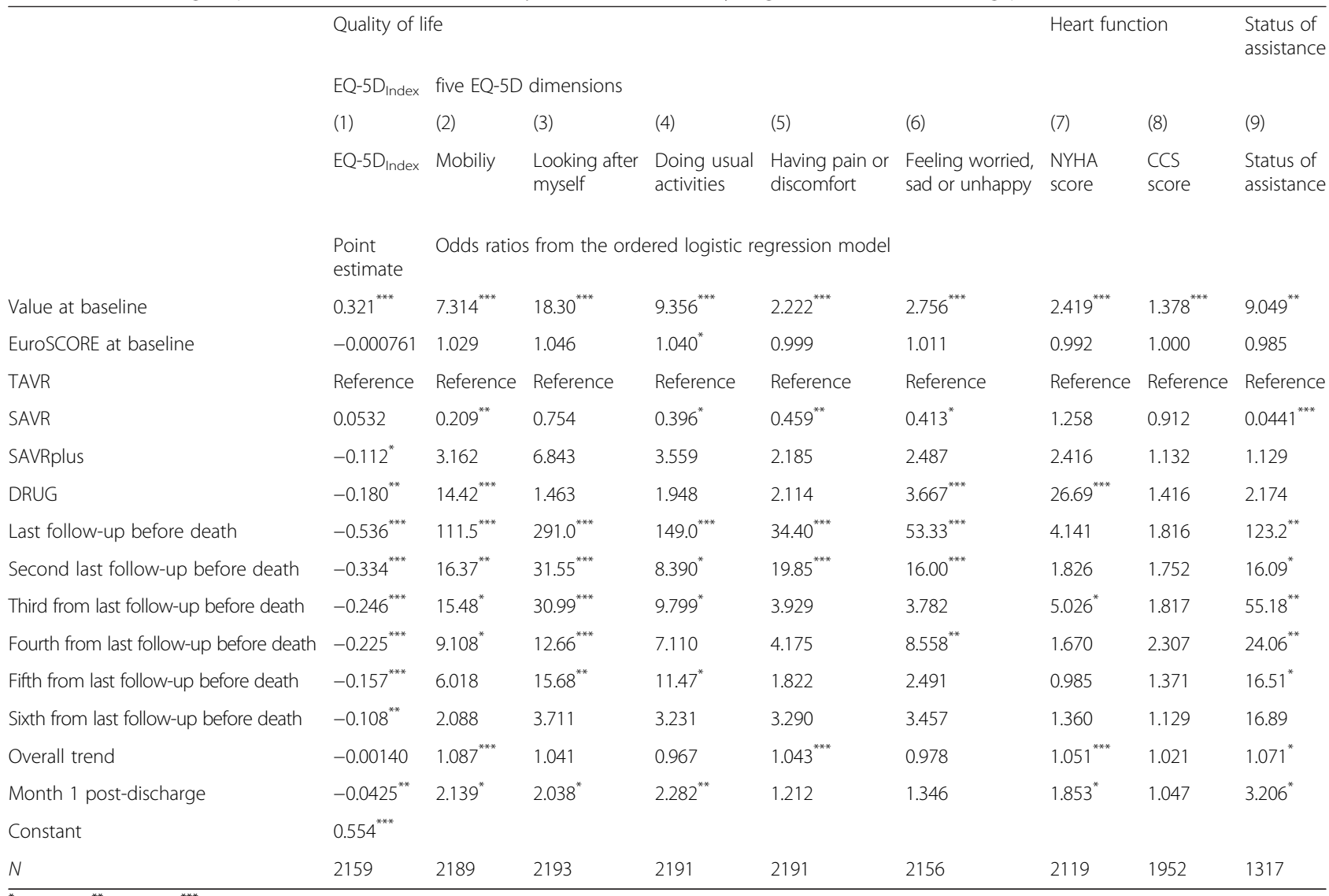

$p<0.05,{ }^{* * *} p<0.01,{ }^{* * *} p<0.001$

The EQ-5D Index is a continuous variable between 0 and $1(0=$ worst state, $1=$ best state). The $5 \mathrm{EQ}-5 \mathrm{D}$ dimensions as shown in Model (2) to model (6) are order categorical variables $(1=$ no problems, $2=$ some problems, $3=$ extreme problems). Canadian Cardiovascular Society (CCS) Angina Grading Scale is an order categorical variable between 1 (angina only during strenuous or prolonged physical activity) and 4 (inability to perform any activity without angina). New York Heart Association (NYHA) Functional Classification is an order categorical variable between 1 (cardiac disease, but no symptoms and no limitation in ordinary physical activity) and 4 (severe limitations, experiences symptoms even while at rest). The current state of assistance is an order categorical variable with 1 (no external help or intra-familial help only), 2 (assisted living and/or home care services) and 3 (short or long-term care or temporal hospitalization). The group SAVRplus includes 17 patients that underwent additional bypass grafting and/or mitral valve replacement

exclude measurements from the last six months prior to death (models (3) and (4)) or we may just ignore the distance in the modelling (models (5) and (6)) and equal EQ- $5 D_{\text {Index }}$ to 0 in the month of death. We can observe similar results for 3 complication groups, but changes for non-ASB and AKIN 3. For non-ASB this seems to be related to the fact that this complication took place in $12 \mathrm{pa}-$ tients, of which two died within three months after event. These two patients were facing the worst possible health state $E Q-5 D_{\text {Index }}=-0.205$ during each follow-up interview after event and before death. Unsurprisingly, the estimated impact of life threatening access side bleeding changed substantially, as these two patients were excluded from the analysis in model (3) and (4). Basically, the results of model (1) to (4) represent the estimated impact of the respective complication on EQ- $5 \mathrm{D}_{\text {Index }}$ values assuming that the patient survives the six months following the event. Model (5) and (6), in contrast, show the estimated impact of the respective complication on EQ-5D Index values for all patients, including those patients who die shortly after the event. That is why, for instance, model (6) returns substantially higher QoL impairments for patients with AKIN than model (2): Model (2) separates prior-to-death impairments from those arising in patients that do not die during the next months, whereas model (6) does not adjust for upcoming death. Of the sixteen patients facing stage 3 AKIN, nine patients died before the first follow-up after and two patients died during month two and three after event.

\section{Discussion}

Due to many potential determinants of patient's QoL after treatment of AS, a careful modelling of longitudinal data is necessary. With such a carefully developed model we were able to demonstrate and quantify short term effects - and nearly only short term effects - of the clinical complications considered. Most interestingly, our findings demonstrate that distance to death is one of 
Table 4 Impact of clinical events on QoL measures among TAVR and SAVR patients

\begin{tabular}{|c|c|c|c|c|c|c|c|c|c|}
\hline & Quality of life & & & & & & Heart fu & inction & Status of \\
\hline & EQ-5D Index & Five EQ-5 & 5D dimensions & & & & & & \\
\hline & (1) & (2) & (3) & (4) & (5) & (6) & (7) & (8) & (9) \\
\hline & $E Q-5 D_{\text {Index }}$ & Mobility & $\begin{array}{l}\text { Looking after } \\
\text { myself }\end{array}$ & $\begin{array}{l}\text { Doing usual } \\
\text { activities }\end{array}$ & $\begin{array}{l}\text { Having pain or } \\
\text { discomfort }\end{array}$ & $\begin{array}{l}\text { Feeling worried, } \\
\text { sad or unhappy }\end{array}$ & $\begin{array}{l}\text { NYHA } \\
\text { score }\end{array}$ & $\begin{array}{l}\text { CCS } \\
\text { score }\end{array}$ & $\begin{array}{l}\text { Status of } \\
\text { assistance }\end{array}$ \\
\hline & Point estimate & Odds rati & ios from the or & dered logistic & regression model & & & & \\
\hline Value at baseline & $0.350^{* * *}$ & $14.19^{* * *}$ & $34.09^{* * *}$ & $10.96^{* * *}$ & $1.671^{*}$ & $2.751^{* * *}$ & $2.457^{* * *}$ & $1.398^{* * *}$ & $10.82^{* *}$ \\
\hline ASB life threatening/disabling & -0.0463 & $12.68^{* *}$ & 0.680 & 0.199 & 2.860 & 0.771 & 0.123 & 0.188 & 0.104 \\
\hline ASB major/minor & $0.0985^{*}$ & 0.587 & 0.499 & $0.201^{* * *}$ & $0.182^{*}$ & $0.121^{*}$ & 0.762 & 0.673 & 0.342 \\
\hline NASB life threatening/disabling & $-0.447^{* * *}$ & $584.6^{* *}$ & 54.93 & 7.752 & 0.739 & $47.86^{*}$ & 1.410 & 1.591 & $86.32^{*}$ \\
\hline NASB major/minor & -0.0199 & 1.188 & 0.688 & 0.597 & 1.311 & 0.573 & 1.180 & 0.813 & 4.088 \\
\hline VASC major/minor & -0.00695 & 0.282 & 0.971 & 2.029 & 0.833 & 2.110 & 1.422 & 0.660 & 6.198 \\
\hline Stroke/TIA & $-0.161^{*}$ & $8.298^{* *}$ & 1.358 & 4.179 & 6.661 & 2.561 & 0.343 & 0.380 & 0.958 \\
\hline AKIN 1 & 0.0659 & 1.270 & 1.104 & 0.357 & 0.430 & 0.742 & 0.547 & 0.601 & 0.718 \\
\hline AKIN 2 & $-0.158^{*}$ & 1.297 & 7.126 & $102.2^{* *}$ & 0.814 & 0.340 & $81.36^{*}$ & $104.2^{* *}$ & 21.79 \\
\hline AKIN 3 & $-0.177^{* *}$ & $15.75^{* * *}$ & $21.53^{* *}$ & $7.419^{*}$ & 2.908 & 3.495 & 1.243 & 1.404 & 1.955 \\
\hline Arrhythmia & -0.0377 & 2.393 & 3.153 & 1.954 & 1.817 & 2.200 & 3.490 & $0.234^{*}$ & 1.270 \\
\hline Other complications & 0.0330 & 2.617 & 0.933 & 0.457 & 0.366 & 0.402 & 1.380 & $5.237^{*}$ & 1.057 \\
\hline Last follow-up before death & $-0.493^{* * *}$ & $81.93^{* * *}$ & $154.9^{* * *}$ & $48.14^{* *}$ & $29.90^{* * *}$ & $32.98^{* * *}$ & 2.877 & 1.335 & $144.8^{* *}$ \\
\hline Second last follow-up before death & $-0.270^{* * *}$ & $11.50^{* *}$ & $23.04^{* * *}$ & 5.949 & $15.13^{* * *}$ & $11.13^{* * *}$ & 1.542 & 1.786 & 12.95 \\
\hline Third from last follow-up before death & $-0.204^{* * *}$ & 8.142 & $17.64^{* *}$ & 4.509 & 1.996 & 3.602 & $3.855^{*}$ & 1.377 & $66.29^{* *}$ \\
\hline Fourth from last follow-up before death & $-0.176^{* * *}$ & $7.797^{*}$ & $11.09^{* *}$ & 5.952 & 2.471 & $7.750^{* *}$ & 1.581 & 2.016 & $23.22^{*}$ \\
\hline Fifth from last follow-up before death & $-0.150^{* * *}$ & 4.843 & $13.36^{* *}$ & 8.091 & 1.600 & 2.446 & 0.926 & 1.217 & $25.23^{*}$ \\
\hline Sixth from last follow-up before death & $-0.104^{*}$ & 1.800 & 3.205 & 2.907 & 3.803 & 2.932 & 1.259 & 1.081 & $35.30^{*}$ \\
\hline Overall trend & -0.00165 & $1.085^{* * *}$ & 1.045 & 0.966 & $1.044^{* * *}$ & 0.983 & $1.056^{* * *}$ & 1.020 & $1.088^{* *}$ \\
\hline Month 1 post-discharge & -0.0233 & 1.602 & 1.433 & $2.066^{*}$ & 1.465 & 1.130 & 1.370 & 1.599 & 2.774 \\
\hline Constant & $0.528^{* * *}$ & & & & & & & & \\
\hline N & 2212 & 2246 & 2256 & 2254 & 2254 & 2219 & 2182 & 2022 & 1357 \\
\hline
\end{tabular}

" $p<0.05,{ }^{* *} p<0.01,{ }^{* * *} p<0.001$

The EQ-5D categorical variables ( $1=$ no problems, $2=$ some problems, $3=$ extreme problems). Canadian Cardiovascular Society (CCS) Angina Grading Scale is an order categorical variable between 1 (angina only during strenuous or prolonged physical activity) and 4 (inability to perform any activity without angina). New York Heart Association (NYHA) Functional Classification is an order categorical variable between 1 (cardiac disease, but no symptoms and no limitation in ordinary physical activity) and 4 (severe limitations, experiences symptoms even while at rest). The current state of assistance is an order categorical variable with 1 (no external help or intra-familial help only), 2 (assisted living and/or home care services) and 3 (short or long-term care or temporal hospitalization). ASB access site bleeding, NASB non-access site bleeding, VASC vascular complication, AKIN acute kidney injury

several factors with clear effects on QoL measures in the elderly population. Our analyses demonstrate a measurable impairment of QoL measures beginning at the sixth from last follow-up (month) before death. Irrespective of the inclusion of time-invariant baseline variables, treatment effects and/or complications, the influence of distance to death remained robust to any specification of the regression models. In order to take into account the effect of distance to death when analyzing QoL measures, repeated QoL measurements and a long follow-up period seem necessary, and detailed information on death during follow-up may be seen as essential.
Unfortunately, these requirements are unmet in the majority of studies analyzing QoL measures among patients with aortic valve stenosis $[3,6-10,12]$, as a number of reviews on the topic identified many (observational) studies to be subject to survivor bias $[7,8,10]$. When it comes to cost-effectiveness of different treatment options among patients with aortic valve stenosis, however, the inclusion of valid QoL measures is indispensable. Most of the available literature on the topic includes QoL measures of the well-known Placement of Aortic Transcatheter Valves (PARTNER) trial [3, 18-29]. The PARTNER trial takes a special place among the literature due to its large patient population and its status 
Table 5 Impact of clinical events on EQ-5D Index among AVR patients accounting for time-to-death

\begin{tabular}{|c|c|c|c|c|c|c|}
\hline & \multicolumn{2}{|c|}{$\begin{array}{l}\text { Time-to-death adjustment } \\
\text { (six months) }\end{array}$} & \multicolumn{2}{|c|}{$\begin{array}{l}\text { Exclusion of cases of mortality } \\
\text { (six months prior to death) }\end{array}$} & \multicolumn{2}{|c|}{$E Q-5 D_{\text {Index }}=0$ in month of death } \\
\hline & $(1)$ & (2) & (3) & (4) & (5) & (6) \\
\hline & EQ-5D Index & EQ-5D Index & EQ-5D Index & EQ-5D Index & EQ-5D Index & EQ-5D Index \\
\hline Value at baseline & $0.348^{* * *}$ & $0.346^{* * *}$ & $0.333^{* * *}$ & $0.331^{* * *}$ & $0.333^{* * *}$ & $0.331^{* * *}$ \\
\hline ASB life threatening/disabling & -0.0593 & $-0.140^{*}$ & 0.0356 & -0.0497 & -0.0599 & -0.121 \\
\hline ... at the second follow-up after event & & $-0.145^{*}$ & & $-0.155^{*}$ & & -0.0993 \\
\hline ... at the third follow-up after event & & $-0.163^{* *}$ & & -0.0950 & & $-0.145^{*}$ \\
\hline NASB life threatening/disabling & $-0.449^{* * *}$ & $-0.493^{* * *}$ & $-0.457^{* * *}$ & $-0.508^{* * *}$ & $-0.448^{* * *}$ & $-0.465^{* * *}$ \\
\hline ... at the second follow-up after event & & -0.114 & & -0.140 & & -0.101 \\
\hline ... at the third follow-up after event & & 0.103 & & 0.0936 & & 0.109 \\
\hline Stroke / TIA & $-0.147^{*}$ & $-0.206^{* *}$ & $-0.145^{*}$ & $-0.210^{* *}$ & $-0.147^{*}$ & $-0.199^{*}$ \\
\hline .... at the second follow-up after event & & -0.123 & & $-0.146^{*}$ & & -0.121 \\
\hline ... at the third follow-up after event & & -0.0319 & & -0.0286 & & -0.0307 \\
\hline AKIN 2 & $-0.167^{*}$ & $-0.226^{* *}$ & $-0.267^{* *}$ & $-0.270^{* *}$ & $-0.169^{*}$ & $-0.272^{* *}$ \\
\hline ... at the second follow-up after event & & -0.142 & & -0.0428 & & $-0.195^{*}$ \\
\hline ... at the third follow-up after event & & 0.0657 & & 0.0150 & & 0.0508 \\
\hline AKIN 3 & $-0.173^{* *}$ & $-0.186^{* *}$ & $-0.235^{* *}$ & $-0.293^{* * *}$ & $-0.381^{* * *}$ & $-0.418^{* * *}$ \\
\hline ... at the second follow-up after event & & -0.113 & & $-0.177^{*}$ & & $-0.235^{* *}$ \\
\hline ... at the third follow-up after event & & -0.00684 & & -0.0338 & & -0.0939 \\
\hline Other complications & 0.00548 & 0.00571 & 0.0134 & 0.0140 & 0.00464 & 0.00368 \\
\hline Last follow-up before death & $-0.493^{* * *}$ & $-0.487^{* * *}$ & & & & \\
\hline Second last follow-up before death & $-0.275^{* * *}$ & $-0.272^{* * *}$ & & & & \\
\hline Third from last follow-up before death & $-0.210^{* * *}$ & $-0.217^{* * *}$ & & & & \\
\hline Fourth from last follow-up before death & $-0.180^{* * *}$ & $-0.189^{* * *}$ & & & & \\
\hline Fifth from last follow-up before death & $-0.154^{* * *}$ & $-0.166^{* * *}$ & & & & \\
\hline Sixth from last follow-up before death & $-0.108^{* *}$ & $-0.116^{* *}$ & & & & \\
\hline Overall trend & -0.00161 & $-0.00222^{* *}$ & $-0.00195^{*}$ & $-0.00249^{* *}$ & $-0.00322^{* * *}$ & $-0.00386^{* * *}$ \\
\hline Month 1 post-discharge & -0.0230 & -0.0283 & -0.0256 & -0.0301 & -0.0163 & -0.0218 \\
\hline Constant & $0.529^{* * *}$ & $0.543^{* * *}$ & $0.548^{* * *}$ & $0.559^{* * *}$ & $0.508^{* * *}$ & $0.523^{* * *}$ \\
\hline$N$ & 2212 & 2212 & 2102 & 2102 & 2250 & 2250 \\
\hline
\end{tabular}

as the first and for a long period only randomized multicenter study of QoL outcomes under medical care, TF-TAVR, TA-TAVR, and SAVR so far. Sehatzadeh et al. [11] summarize the body of literature on the medical and QoL results of this trial, as well as the incremental cost-effectiveness ratios of the various techniques, at two years of follow-up.

Strikingly, within the boundaries of the study design and inclusion/exclusion criteria, there appear to be a number of important differences in patients from either the TAVR or the other groups [13]. Therefore, it may be misleading to make direct comparisons of the results between the groups. Moreover, our initial study design included the enrollment of drug patients, analogous to the conservative treatment arm from PARTNER B [30], but it soon became evident that these patients were rarely considered inoperable and were typically offered TAVR. This directly reflects the current clinical practice and demonstrates the very limited number of patients presenting with a "true" contraindication for TAVR or SAVR. However, it remains unclear whether these "borderline" patients are a consequence of a shift in perceptions about eligibility for TAVR or surgery, and if so what impact their inclusion will have on mortality and morbidity affecting comparisons with pivotal studies such as PARTNER [3, 20, 30]. 
Please note that there are a number of limitations: First of all, between-group differences in QoL measures should not, or at least only in part, be interpreted as treatment effects, as the different treatment groups are not randomly assigned but subject to a risk-driven patient selection which may not be fully addressed by the applied baseline adjustment. Secondly, there are substantial decreases in QoL measurement compliance over the two year period and we may not assure whether dropouts were entirely noninformative.

\section{Conclusion}

Finally, cost-effectiveness analyses highly depend on valid information regarding the impact of relevant clinical events. Interestingly, our results indicate that in the present dataset of elderly patients, only few complications had a sustained long-term impact on QoL. Again, the appropriate inclusion of death seems crucial in terms of model selection for estimating the impact of clinical complications on QoL values.

\section{Endnotes}

${ }^{1}$ Neither the extension of the time period before death to seven or more follow-up months before death, nor the extension of the post-discharge effect to two or more months showed a measurable impact on QoL measures and was therefore excluded from the regression models.

${ }^{2}$ The inclusion of interaction terms between EQ$5 \mathrm{D}_{\text {Index }}$ values at baseline and time showed no substantial differences regarding their impact on EQ-5D $D_{\text {Index }}$ values at month 1 , during year 1 post-discharge, or later than one year post-discharge.

${ }^{3}$ Extension of the lagged effect did not show an impact on QoL measures and was therefore excluded from the regression models.

\section{Abbreviations \\ AKIN, acute kidney injury; AS, aortic valve stenosis; CCS, canadian cardiovascular society; EACTS, european association for cardio-thoracic surgery; ESC, european society of cardiology; HRQOL, health-related quality of life; non-ASB, non-access site bleeding; NYHA, New York heart association; QoL, quality of life; SAVR, surgical aortic valve replacement; TAVR, transcatheter aortic valve replacement; TCCT, TAVI calculation of costs trial; VARC, valve academic research consortium}

\section{Acknowledgements}

The authors express their gratitude to staff members Melanie Avlar, Jutta Schmitz, Judith Anderl and Christiane Rack for data collection.

\section{Funding}

The TCCT study was funded by Edwards Lifesciences SA

\section{Availability of data and materials}

Individual patient datasets cannot be made publically available due to data protection requirements.

\section{Authors' contribution}

KK: Substantial contributions to conception and design, acquisition of data, analysis and Interpretation of data, drafting and revising the article, final approval of the version to be published. AG: Substantial contributions to conception and design, revising the article, final approval of the version to be published. HB: Substantial contributions to conception and design, revising the article, final approval of the version to be published. CvzM: Substantial contributions to conception and design, revising the article, final approval of the version to be published. PH: Substantial contributions to conception and design, revising the article, final approval of the version to be published. WV: Substantial contributions to conception and design, revising the article, final approval of the version to be published. FB: Substantial contributions to conception and design, revising the article, final approval of the version to be published. MZ: Substantial contributions to conception and design, revising the article, final approval of the version to be published. CB: Substantial contributions to conception and design, revising the article, final approval of the version to be published. JR: Substantial contributions to conception and design, acquisition of data, analysis and Interpretation of data, drafting and revising the article, final approval of the version to be published.

\section{Competing interests}

No restrictions were placed on either the design or the presentation of results, or the interpretation of data.

\section{Consent for publication}

Not applicable.

\section{Ethics approval and consent to participate}

The study design and patient consent procedure for this study were cleared by the Research Ethics Committee of the Albert-Ludwigs-Universität Freiburg, Germany $(52 / 11)$.

\section{Registration number}

This study was registerd in the German Clinical Trial Register under the number DRKS00000797.

\section{Author details}

${ }^{1}$ Institute of Medical Biometry and Statistics, Faculty of Medicine and Medical Center - University of Freiburg, Stefan-Meier-Str. 26, D-79104 Freiburg, Germany. ${ }^{2}$ Department of Cardiology, Heart Center Freiburg University, Freiburg, Germany. ${ }^{3}$ Department of Cardiovascular Surgery, Robert-Bosch-Krankenhaus, Stuttgart, Germany. ${ }^{4}$ Department of Cardiovascular Surgery, Heart Center Freiburg University, Freiburg, Germany.

Received: 6 January 2016 Accepted: 17 July 2016

Published online: 26 July 2016

\section{References}

1. Thaden JJ, Nkomo VT, Enriquez-Sarano M. The global burden of aortic stenosis. Prog Cardiovasc Dis. 2014;56(6):565-71.

2. lung B, Vahanian A. Epidemiology of acquired valvular heart disease. Can J Cardiol. 2014;30(9):962-70.

3. Reynolds MR, Magnuson EA, Wang K, Thourani VH, Williams M, Zajarias A, Rihal CS, Brown DL, Smith CR, Leon MB. Health-related quality of life after transcatheter or surgical aortic valve replacement in high-risk patients with severe aortic stenosis: results from the PARTNER (Placement of AoRTic TraNscathetER Valve) Trial (Cohort A). J Am Coll Cardiol. 2012;60(6):548-58.

4. Vigl M, Niggemeyer E, Hager A, Schwedler G, Kropf S, Bauer U. The importance of socio-demographic factors for the quality of life of adults with congenital heart disease. Qual Life Res. 2011;20(2):169-77.

5. Schoormans D, Mulder BJ, van Melle JP, Pieper PG, van Dijk AP, Sieswerda GT, Hulsbergen-Zwarts MS, Plokker TH, Brunninkhuis LG, Vliegen HW. Illness perceptions of adults with congenital heart disease and their predictive value for quality of life two years later. Eur J Cardiovasc Nurs. 2014;13(1):86-94.

6. Chatterjee S, Kumbhani DJ, Sardar P, Chakraborty A, Biondi-Zoccai G, Sabharwal MS, Ro R, Pratap B, Bavishi CP, Bangalore S. Health-related quality of life after transcatheter or surgical aortic valve replacement in high-risk patients with severe aortic stenosis: an updated review of literature. Curr Cardiol Rep. 2014:16(4):473

7. Deutsch MA, Bleiziffer S, Elhmidi Y, Piazza N, Voss B, Lange R, Krane M. Beyond adding years to life: health-related quality-of-life and functional outcomes in patients with severe aortic valve stenosis at high surgical risk undergoing transcatheter aortic valve replacement. Curr Cardiol Rev. 2013;9(4):281-94 
8. Georgiadou P, Sbarouni E, Karavolias GK, Voudris V. Transcatheter aortic valve implantation: restoring the qualities of life in old age. Age Ageing. 2013;42(1):21-6.

9. Horrocks J, Closs J, Astin F. Quality of life in older adults with aortic stenosis: a narrative review. Int J Older People Nurs. 2014;9(3):227-46.

10. Kim CA, Rasania SP, Afilalo J, Popma JJ, Lipsitz LA, Kim DH. Functional status and quality of life after transcatheter aortic valve replacement: a systematic review. Ann Intern Med. 2014;160(4):243-54.

11. Sehatzadeh S, Doble B, Xie F, Blackhouse G, Campbell K, Kaulback K, Chandra K, Goeree R. Transcatheter aortic valve implantation (TAVI) for treatment of aortic valve stenosis: an evidence update. Ont Health Technol Assess Ser. 2013;13(1):1-40.

12. Shan L, Saxena A, McMahon R, Wilson A, Newcomb A. A systematic review on the quality of life benefits after aortic valve replacement in the elderly. J Thorac Cardiovasc Surg. 2013;145(5):1173-89.

13. Kaier K, Gutmann A, Vach W, Sorg S, Siepe M, von Zur Mühlen C, Moser M, Blanke P, Beyersdorf F, Zehender M, Bode C, Reinöhl J. " Heart Team" decision making in elderly patients with symptomatic aortic valve stenosis who underwent AVR or TAVI-a look behind the curtain. Results of the prospective TAVI Calculation of Costs Trial (TCCT). Eurolntervention. 2014. doi:10.4244/EIJY14M12 06. [Epub ahead of print].

14. Walters SJ, Brazier JE. Comparison of the minimally important difference for two health state utility measures: EQ-5D and SF-6D. Qual Life Res. 2005;14(6):1523-32

15. Greiner W, Claes C, Busschbach JJV, von der Schulenburg J-MG. Validating the EQ-5D with time trade off for the German population. Eur J Health Econ. 2005;6(2):124-30.

16. Kappetein AP, Head SJ, Genereux P, Piazza N, Van Mieghem NM, Blackstone EH, Brott TG, Cohen DJ, Cutlip DE, van Es GA. Updated standardized endpoint definitions for transcatheter aortic valve implantation: the Valve Academic Research Consortium-2 consensus document. J Thorac Cardiovasc Surg. 2013;145(1):6-23.

17. Vahanian A, Alfieri O, Andreotti F, Antunes MJ, Baron-Esquivias G, Baumgartner $\mathrm{H}$, Borger MA, Carrel TP, De Bonis M, Evangelista A. Guidelines on the management of valvular heart disease (version 2012) The Joint Task Force on the Management of Valvular Heart Disease of the European Society of Cardiology (ESC) and the European Association for Cardio-Thoracic Surgery (EACTS). Eur Heart J. 2012;33(19):2451-96.

18. Doble B, Blackhouse G, Goeree R, Xie F. Cost-effectiveness of the Edwards SAPIEN transcatheter heart valve compared with standard management and surgical aortic valve replacement in patients with severe symptomatic aortic stenosis: a Canadian perspective. J Thorac Cardiovasc Surg. 2013;146(1):52-60

19. Neyt M, Van Brabandt H, Devriese S, Van De Sande S. A cost-utility analysis of transcatheter aortic valve implantation in Belgium: focusing on a welldefined and identifiable population. BMJ open. 2012;2(3):e001032.

20. Reynolds MR, Magnuson EA, Lei Y, Wang K, Vilain K, Li H, Walczak J, Pinto DS, Thourani VH, Svensson LG. Cost-effectiveness of transcatheter aortic valve replacement compared with surgical aortic valve replacement in high-risk patients with severe aortic stenosis: results of the PARTNER (Placement of Aortic Transcatheter Valves) trial (Cohort A). J Am Coll Cardiol. 2012;60(25):2683-92.

21. Simons CT, Cipriano LE, Shah RU, Garber AM, Owens DK, Hlatky MA. Transcatheter aortic valve replacement in nonsurgical candidates with severe, symptomatic aortic stenosis a cost-effectiveness analysis. Circ Cardiovasc Qual Outcomes. 2013;6(4):419-28.

22. Orlando R, Pennant M, Rooney S, Khogali S, Bayliss S, Hassan A, Moore D, Barton P. Cost-effectiveness of transcatheter aortic valve implantation (TAVI) for aortic stenosis in patients who are high risk or contraindicated for surgery: a model-based economic evaluation. Health Technol Assess. 2013;17(33):1-86.

23. Brecker S, Mealing S, Padhiar A, Eaton J, Sculpher M, Bosmans J, Gerckens UJ, Wenaweser P, Tamburino C, Bleiziffer S. Cost-utility of transcatheter aortic valve implantation for inoperable patients with severe aortic stenosis treated by medical management: a UK cost-utility analysis based on patient-level data from the ADVANCE study. Open Heart. 2014;1(1):e000155.

24. Eaton J, Mealing S, Thompson J, Moat N, Kappetein P, Piazza N, Busca R, Osnabrugge $\mathrm{R}$. Is transcatheter aortic valve implantation (TAVI) a costeffective treatment in patients who are ineligible for surgical aortic valve replacement? A systematic review of economic evaluations. J Med Econ. 2014:17(5):365-75.
25. Indraratna P, Ang SC, Gada H, Yan TD, Manganas C, Bannon P, Cao C. Systematic review of the cost-effectiveness of transcatheter aortic valve implantation. J Thorac Cardiovasc Surg. 2014;148(2):509-14.

26. Gada H, Kapadia SR, Tuzcu EM, Svensson LG, Marwick TH. Markov model for selection of aortic valve replacement versus transcatheter aortic valve implantation (without replacement) in high-risk patients. Am J Cardiol. 2012;109(9):1326-33.

27. Fairbairn TA, Meads DM, Hulme C, Mather AN, Plein S, Blackman DJ, Greenwood JP. The cost-effectiveness of transcatheter aortic valve implantation versus surgical aortic valve replacement in patients with severe aortic stenosis at high operative risk. Heart. 2013;99(13):914-20.

28. Gada H, Agarwal S, Marwick TH. Perspective on the cost-effectiveness of transapical aortic valve implantation in high-risk patients: Outcomes of a decision-analytic model. Ann Cardiothorac Surg. 2012;1(2):145.

29. Watt M, Mealing S, Eaton J, Piazza N, Moat N, Brasseur P, Palmer S, Sculpher M. Cost-effectiveness of transcatheter aortic valve replacement in patients ineligible for conventional aortic valve replacement. Heart. 2012;98(5):370-6

30. Reynolds MR, Magnuson EA, Wang K, Lei Y, Vilain K, Walczak J, Kodali SK, Lasala JM, O'Neill WW, Davidson CJ. Cost-effectiveness of transcatheter aortic valve replacement compared with standard care among inoperable patients with severe aortic stenosis results from the placement of aortic transcatheter valves (PARTNER) trial (Cohort B). Circulation. 2012;125(9):1102-9.

\section{Submit your next manuscript to BioMed Central and we will help you at every step:}

- We accept pre-submission inquiries

- Our selector tool helps you to find the most relevant journal

- We provide round the clock customer support

- Convenient online submission

- Thorough peer review

- Inclusion in PubMed and all major indexing services

- Maximum visibility for your research

Submit your manuscript at www.biomedcentral.com/submit
) Biomed Central 